\title{
DESDE LA FICHA DE PROTECCIÓN SOCIAL AL REGISTRO SOCIAL DE HOGARES, EL NUEVO INSTRUMENTO DE FOCALIZACIÓN EN CHILE. UNA PERSPECTIVA DESDE LOS ACTORES LOCALES ${ }^{1}$
}

\author{
Jaime Contreras Álvarez ${ }^{(\cdot)}$ \\ Katherine Figueroa Aillañir (••) \\ Universidad de Concepción (Chile)
}

\section{RESUMEN}

La presente investigación busca ahondar desde la perspectiva de los actores municipales, en la implementación del nuevo Registro Social de Hogares, como mecanismo de selección de beneficiarios, en las categorías de comportamiento de los usuarios y principales cambios del sistema. Se utilizaron encuestas a equipos comunales de las regiones de Biobío y Ñuble y entrevistas a actores claves. Se concluye que las familias continúan entregando información tergiversada al sistema, y una mayor incidencia del patrimonio en los criterios de focalización del instrumento, no obstante, es valorado positivamente por los actores locales.

\section{PALABRAS CLAVE:}

Registro Social de Hogares, Ficha Protección Social, Patrimonio, Equipos Comunales.

\section{KEY WORDS:}

Social Household Registry, Social Protection Tab, Heritage, Municipal Teams.

\footnotetext{
(•) E-mail: jaimecontreras@udec.cl

(••) E-mail: katfigueroa@udec.cl
}

RECEPCIÓN: 05/04/18

ACEPTACIÓN FINAL: 13/07/18 


\section{1 intRODUCCIŌN}

El presente artículo pretende analizar las modificaciones al sistema de focalización de programas sociales en Chile, observadas desde los equipos municipales, comparando la Ficha de Protección Social (FPS) versus el nuevo Registro Social de Hogares (RSH), tomando como información relevante para caracterizar estas modificaciones, los relatos y percepciones de funcionarios y actores claves municipales, responsables de la implementación del RSH en las regiones de Biobío y Núble.

El nuevo instrumento reemplaza la Ficha de Protección Social (FPS), y se caracteriza por usar bases de datos administrativas otorgadas por servicios públicos, para caracterizar los medios, necesidades e ingresos que una persona y su familia poseen. Se revisaron dos categorías de análisis, en primer lugar, el "comportamiento de los usuarios", el que concluye que se mantienen lógicas de información tergiversada para aprovechar beneficios sociales, y a la vez una falta de fiscalización sobre este tipo de conductas. En segundo lugar, se analizaron los principales cambios que se evidencian en el sistema $\mathrm{RSH}$, destacando la confiabilidad de la información en materia de ingresos, discapacidad y educación, además de la transparencia de los tramos de caracterización socioeconómica para cada familia. Lo anterior, demuestra una importante valoración positiva que desarrollan los funcionarios municipales respecto al nuevo instrumento y las modificaciones con el antiguo sistema FPS. 


\section{PROBLEMATIZACIŌN}

El modelo chileno de asignación de beneficios sociales desde la época de la dictadura cívico-militar asume un rol de focalización de la política social, basado en modelos liberales-residuales (Ruvalcaba \& Alfredo, 2006)utilizando la ficha CAS como instrumento de focalización(Larrañaga, Falck, Herrera, \& Telias, 2014), la cual seleccionaba beneficiarios para el otorgamiento de los subsidios otorgados en la época, preferentemente a familias que se encontraran en condición de pobreza, entendida ésta como la carencia material de viviendas. "La Ficha fue un símbolo del cambio de paradigma del Estado de Bienestar, desde uno que distribuía beneficios según afiliación laboral a otro de carácter residual, que asistía a los pobres" (Larrañaga, 2010, p. 24).

El instrumento comenzó a ser utilizado el año 1979 y una década más tarde se le hizo un ajuste al modelo de cálculo, pasando a llamarse CAS-2, la cual incluía modificaciones en diversas variables, y "se incorporó la vivienda como unidad de aplicación y a la familia como unidad de análisis» (Herrera, Larrañaga, \& Telias, 2010, p. 269)

Luego, en el primer mandato de la ex Presidenta Michelle Bachelet, se incorpora en el Plan de Gobierno, instalar un Sistema de Protección Social, y para ello se modifica el instrumento de focalización, pasando desde la Ficha CAS-2 a la Ficha de Protección Social (FPS). El nuevo instrumento comenzó a operar el año 2006 y modifica el paradigma de beneficiario de la política social, priorizando las condiciones de riesgo social de una familia, versus las condiciones materiales, de esta forma, el instrumento asignaba puntajes de acuerdo a los niveles de vulnerabilidad que el grupo familiar poseía. Este nuevo instrumento (FPS), lo continuaron aplicando los municipios del país, mediante visita a la familia en su vivienda, donde se aplicaba el instrumento en formato físico para luego ser digitado en una plataforma implementada por el Ministerio de Planificación de la época.

El puntaje se calculaba mediante un algoritmo que comparaba la Capacidad Generadora de Ingresos (CGI) de los miembros del hogar versus un Índice de Necesidades de sus integrantes. La Capacidad Generadora de Ingresos consideraba entre otros elementos la capacidad de trabajo, observando la escolaridad, edad, experiencia laboral, tipo de filiación laboral, entre otros. (Herrera et al., 2010) También se incorporaron variables de dispersión territorial y desempleo, que pudieran afectar el conseguir trabajo, y las condiciones de vulnerabilidad como infancia, discapacidad, cuidado de personas postradas, entre otros, los cuales restringían la capacidad de generar ingreso. El cálculo era diferenciado para hombres o mujeres y por tipos de contratos de trabajo (indefinidos o plazo fijo), y condición de trabajo (dependiente o independiente). El puntaje 
no consideró las condiciones de riqueza (capital) para efectuar el cálculo de puntaje. (Herrera et al., 2010; Larrañaga et al., 2014).

El método de recogida de información fue efectuado mediante procedimientos de autoreporte, donde cada familia informaba al funcionario municipal sobre los diferentes componentes que evaluaba la FPS, «las familias tenía la obligación de no ocultar información ni entregar antecedentes falsos; deben firmar una declaración en la misma FPS que señalaba que los datos declarados eran fidedignos y que autorizaban a MIDEPLAN a verificar la información" (Covarrubias, lararrazaval, \& Morandé, 2011, p. 194) . A su vez, el funcionario municipal, podía requerir ciertos documentos para corroborar la información entregada. La información digitada en la plataforma sólo era validada contra las bases de datos del Registro Civil, Superintendencia de Seguridad Social (SUSESO), el Instituto de Previsión Social y toda la demás información autodeclarada se presumía como verdadera.

"Las validaciones de la información de la FPS se realizaban a través de dos modalidades. Una primera modalidad por sistema, en la cual este arrojaban antecedentes de las personas y familias de acuerdo con las fuentes de información del registro civil, y la información respecto de ingresos provenientes de jubilaciones, pensiones y montepíos a través del INP (...) Una segunda modalidad de actualización de los datos es a través de solicitud, es decir, cualquier otro antecedente o cambio en la situación de una persona o familia que el encargado comunal del sistema deba actualizar o consagrar de acuerdo con la normativa vigente" (Covarrubias et al., 2011, p. 195)

A pesar de la capacidad del funcionario de cuestionar la información, este procedimiento generó que las personas tendieran a manipular la información entregada, tergiversando o falseando información para lograr disminuir su puntaje y alcanzar los beneficios sociales(Ministerio de Desarrollo Social, 2010) «A pesar de estas medidas, como ya se analizó, la falta de actualización y validación periódica de la información permitió que las familias manipularan de alguna manera sus datos para ocultar su situación real” (Covarrubias et al., 2011, p. 194). De esta forma, el instrumento se mal utilizó para alcanzar los diferentes beneficios sociales y las familias se arriesgaban a mentir, y ser sancionadas con multas. «La Ley 20.739 de 2009, establece multas de hasta 20 UTM para quienes entreguen información falsa durante el proceso de encuesta para la aplicación del instrumento de caracterización socioeconómica. A la fecha no hay registros de que se haya aplicado esta sanción» (Ministerio de Desarrollo Social, 2010, p. 56) 
Si bien, la FPS fue un mejoramiento en el instrumento de focalización, ésta no estuvo ajena a críticas desde la mirada de la implementación, pues al igual que la ficha CAS era un instrumento de auto declaración, por ende, cada Jefe de Familia indicaba las características de su grupo familiar, sin existir un control sobre la información entregada, lo que tendió a incrementar sostenidamente los grupos más vulnerables de forma paulatina, llegando a concentrarse el 35\% de la población con FPS dentro del rango más vulnerable

En base a esta mala utilización del instrumento, el año 2010, se conforma un Comité de Expertos, convocado por el Presidente Piñera. El Comité fue conformado por funcionarios de Gobierno, académicos y personas del tercer sector y se estableció como su mandato "analizar el instrumento actual en su diseño e implementación, formular propuestas de mejoramiento para los procesos de aplicación de la FPS y elaborar recomendaciones relacionadas con el uso de los puntajes por parte de las instituciones que administran los programas sociales" (Ministerio de Desarrollo Social, 2010)

El Comité entregó una serie de recomendaciones que fueron absorbidas por el naciente Ministerio de Desarrollo Social, mediante la División de Focalización de la nueva Subsecretaría de Servicios Sociales, desarrollando una inversión de US\$ 35M en la creación de un nuevo instrumento denominado "Ficha Social", la cual recogía esta gamma de debilidades, cruzando información con bases de datos externas como el Servicio de Impuestos Internos, Ministerio de Educación, Conservador de Bienes Raíces, etc. Finalmente, en enero de 2014, el entonces Ministro de Desarrollo Social, Bruno Baranda informa que no se aplicará el instrumento y que se dejará toda la información para la siguiente administración, correspondiente al segundo mandato de Michelle Bachelet. De acuerdo al Informe de Auditoría de la Contraloría General de la República (2015) se establece que existieron retrasos en la implementación de plataformas informáticas que dieran soporte al nuevo registro y no se cumplieron los compromisos de los 191 Convenios suscritos con municipios del país.

Finalmente, al asumir el segundo periodo de la ex Presidenta Michelle Bachelet, en su programa de Gobierno, anuncia la creación de un nuevo instrumento de focalización, basado en principios de universalidad con exclusión de la extrema riqueza. Este instrumento denominado Registro Social de Hogares (RSH), se establece como un nuevo "Sistema de Apoyo a la Selección de Usuarios de Prestaciones Sociales" de esta forma, el instrumento sería un soporte para que los diversos programas sociales pudieran seleccionar los beneficiarios. El RSH reemplaza a la Ficha de Protección Social, y el objetivo consistió en, 
"apoyar los distintos procesos de selección de usuarios de beneficios, prestaciones y programas sociales, a través de la provisión de un conjunto amplio de información, principalmente provenientes de registros administrativos del Estado, entre la cual se incluye la construcción de una Calificación Socioeconómica de los hogares" (Berner, 2016a, p. 3)

De esta forma se dicta el Decreto Supremo 22 del 27 de agosto de 2015, del Ministerio de Desarrollo Social que regula el funcionamiento de este nuevo Registro Social de Hogares y comenzó a funcionar el 01 de enero del año 2016, tomando la información existente de la antigua Ficha de Protección Social y la información que dejó la Ficha Social, sumando una serie de bases de datos que fueron entregadas por los servicios, luego que se aprobara la ley 20.530 de 2011 que creó el Ministerio de Desarrollo Social, otorgándole la posibilidad de solicitar a los demás ministerios, senvicios o entidades públicas la entrega de la información disponible para utilizar en este nuevo instrumento.

El Registro Social de Hogares, actualmente considera para confeccionar la Clasificación Socioeconómica (C.S.E), información otorgada mediante bases de datos desde la Superintendencia de Pensiones, la Administradora Fondo de Cesantía, Superintendencia de Salud, Instituto de Previsión Social, Servicio de Impuestos Internos, Ministerio de Educación, Registro Civil y las Bases de Datos del Ministerio de Desarrollo Social (Berner, 2016b)

La Ficha de Protección Social dejó de operar desde el 31 de diciembre de 2015 y el nuevo instrumento comenzó a operar en los municipios del país de forma inmediata desde el 01 de enero de 2016. Para el cálculo de la CSE, se utiliza la información administrativa (bases de datos) más la información autodeclarada en formulario. La Calificación Socio Económica se otorga a cada hogar, clasificándolos en tramos agrupados en deciles, excepto el primero grupo que inicia con el 40\% (Ministerio de Desarrollo Social, 2016b). Para dicho cálculo, se consideran,

Los ingresos del trabajo (dependiente e independiente), capital (físico y financiero) y pensiones (contributivas y no contributivas) que se obtengan del RSH para cada integrante del hogar, ya sea mediante información de bases de datos administrativas (Administradora de Fondos de Cesantía, Superintendencia de Pensiones, Superintendencia de Salud o Servicio de Impuestos Internos) o datos autorreportados en caso de no existir información administrativa. (Candia \& Henoch, 2017, p. 10) 
Luego, el ingreso es contrastado contra el Índice de Necesidades obteniendo el Ingreso Equivalente Corregido para el Hogar, de esta forma usando ese indicador se clasifica al hogar en tramos que van desde el $40 \%$ al $100 \%$. Finalmente, la clasificación es reordenada mediante un procedimiento, denominado por el Ministerio, como "test de medios", que corresponde "a la evaluación de bienes y servicios que posee o accede un hogar (distintos al ingreso) que permitiría inferir su nivel socioeconómico, y eventualmente concluir que el tramo asignado podría subrreportar la situación de un hogar» (Candia \& Henoch, 2017). El Test de Medios que aplica el instrumento considera analizar cotización de salud, mensualidad en educación, valor de vehículos y valor de bienes raíces, que se establecen como patrimonio o capacidad de ingreso. Se da la excepción con personas mayores y sus viviendas, hogares donde existan personas en situación de discapacidad, o vehículos comerciales.

La base conceptual del instrumento y usando las clasificaciones que entrega Coady, Grosh, Hoddinott (2004) sobre este tipo de mecanismos, el caso chileno muestra históricamente el uso de herramientas consideradas como del tipo evaluación individual, bajo lógicas de proxy means test (comprobación sustitutiva de medios de vida), este mecanismo permite estimar el ingreso o el consumo cuando las mediciones precisas no están disponibles o son difíciles de obtener. En muchas situaciones, es posible que saber cuánto gana o gasta una familia cada mes (World Bank, s. f.). es decir, los usos de estas variables se utilizan para la focalización individual o familiar. "La prueba de medios de subsistencia con variables proxy (proxy means test), parte de variables consideradas relevantes y verificables, a las cuales asigna un puntaje para suministrar una aproximación de la capacidad de pago" (Departamento Nacional de Planeación, 2007, p. 10). Dichas variables fueron utilizadas en la Ficha de Protección Social, sin embargo, el nuevo Registro Social de Hogares, pasa a ser un mecanismo mean test, o test directo de medios, es decir, al usar fuentes de información confiable elimina las variables subjetivas para el cálculo de puntaje, en este caso, usando bases de datos administrativas.

El mecanismos de Proxy Meanstests, sigue siendo un mecanismo utilizado a nivel latinoamericano, como el caso colombiano con el SISBEN, México con el Padrón Único de Beneficiarios administrado por la SEDESOL, Brasil con el Catastro Único para focalización de bolsa familia, Costa Rica con el Sistema de Información de la Población Objetivo (SIPO), etc. (Azevedo, Bouillon, \& lararrazaval, 2011; Departamento Nacional de Planeación, 2007), por ende, ambas metodologías son mecanismos que permiten conciliar los programas 
residuales de protección social, basados en la focalización de grupos de población previamente definidos como prioritarios.

Este nuevo instrumento lleva dos años en funcionamiento, por lo tanto, la presente investigación busca ahondar desde la perspectiva de los actores municipales de las regiones de Biobío y Ñuble, el comportamiento de los usuarios del nuevo sistema, y los principales cambios que evidencian entre la antigua FPS y el nuevo RSH.

\section{METODOLOGÍA}

El propósito de la investigación, fue analizar las categorías asociadas al comportamiento de los usuarios y principales modificaciones del Registro Social de Hogares, explorando desde la percepción de actores claves de la región del Biobío y Nuble. Para ello, la investigación consideró un diseño no experimental, descriptivo, transversal, utilizando una metodología mixta. Para efectos del análisis se utilizó un instrumento cuantitativo, donde la unidad de análisis fueron los equipos comunales del Registro Social de Hogares de la región del Biobío y Ñuble. La muestra consideró los equipos comunales de los 54 municipios, que corresponde al universo de actores. Se utilizó como instrumento de recolección de información, un cuestionario cerrado en formato digital, enviado a la base de datos de correos electrónicos de Encargados Comunales del Registro Social de Hogares y los respectivos equipos comunales, contestando 95 personas el instrumento, correspondientes a 47 municipios de ambas regiones. Al interior de la encuesta, se construyó una submuestra, de aquellos funcionarios municipales que habían trabajado con el antiguo sistema FPS y aquellos que sólo conocían el Registro Social de Hogares (RSH).

Terminada la aplicación de las encuestas, se avanzó en entrevistas exploratorias, con pauta de preguntas semiestructurada, para explorar los resultados de las encuestas. Los actores claves fueron seleccionados al azar en base a trayectoria y experiencia en procesos de estratificación en ambas regiones, seleccionado 6 entrevistados con más de 5 años de trabajo en la temática y que dieran representatividad territorial de las provincias de Concepción, Arauco, Núble y Biobío. El análisis de la información fue desarrollado mediante triangulación de información, usando software SPSS V.21 y software Atlas.ti V.8.0, y utilizando matriz de categorías previamente establecidas en base al diagnóstico del Comité de Expertos en Ficha de Protección Social (2010), convocado por el ex Presidente Sebastián Piñera en el año 2010, y que estableció los principales 
lineamientos que debía tener el nuevo instrumento de estratificación social. De esta forma, la presente publicación analiza las categorías "Comportamiento de los Usuarios" y "Modificaciones al Sistema de Estratificación".

\section{Resultados}

\subsection{COMPORTAMIENTO DE LOS USUARIOS}

Una de las principales conclusiones del Comité de Expertos de Ficha de Protección Social (2015), establece que las personas en el proceso de autodeclaración del instrumento, tergiversan información, entregando datos falsos con intención de obtener beneficios sociales.

"Las principales dificultades radican en el reporte de las variables en la encuesta, por la existencia de comportamientos fraudulentos de beneficiarios u operadores del sistema que intentan alterar la información con la finalidad de bajar los puntajes y acceder a los beneficios sociales, distorsionando la focalización que produce la FPS". (p.4)

Debido a las características de los modelos residuales o liberales, orientados a la focalización de personas que cumplan ciertos requisitos, como carencia, pobreza o vulnerabilidad, las personas tienden a falsear información para mantenerse dentro del grupo o estrato socioeconómico, pues de no hacerlo, pierden el beneficio social o la posibilidad de ingresar a una determina prestación del Estado. Este mecanismo es propio de Estados de Bienestar que no adhieren a lógicas de Universalidad, sino a la focalización o discriminación positiva. Esta conducta analizada por Bowles, Durlauf, \& Hoff (2016) denominada "trampa de la pobreza" tiende a repetirse en modelos de bienestar liberales como el caso chileno, donde se aplican instrumentos de focalización, pues el instrumento tiende a forzar que las personas no salgan de su condición de pobreza. Señala el Comité de Expertos de la Ficha de Protección Social «De alguna manera, esto podría generar una especia de trampa de la pobreza ya que desde el punto de vista de los beneficiarios que se encuentran en los límites de estos umbrales, es más conveniente mantener su condición de pobreza que incrementar su esfuerzo por salir de ella (Ministerio de Desarrollo Social, 2010, p. 14).

La implementación del nuevo Registro Social de Hogares buscó eliminar esta situación, contrastando la información entregada por el usuario, contra bases de datos administrativas, sin embargo, a la opinión de los equipos 
comunales, este tipo de conductas sigue ocurriendo. Frente a la afirmación que "Los usuarios entregan información falsa para la obtención de beneficios sociales" un $89 \%$ de los encuestados está de acuerdo con dicha afirmación.

\section{Gráfico 1.}

Entrega de Información Falsa

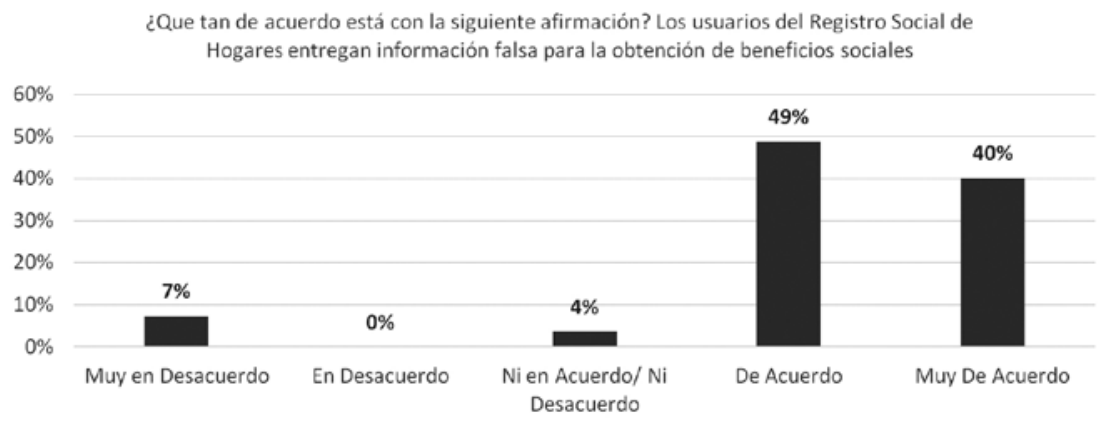

Fuente: Encuesta a encargados comunales del Registro Social de Hogares

A la submuestra de encargados comunales que habían aplicado Ficha de Protección Social antes de la implementación del RSH, (Gráfico 2) se les consultó su percepción sobre la entrega de información falsa en la sección de auto declaración del instrumento, y a pesar que sigue siendo una conducta desarrollada por los usuarios, éstos concuerdan en que ha tendido a disminuir con la implementación del nuevo sistema. Por su parte, los entrevistados concuerdan en señalar que las familias siguen entregando información falsa, pues este tipo de situación, se ha tendido a transformar en un hábito permanente del usuario del sistema.

"yo creo que, ehm..., existe la costumbre después de decenios de haber estado funcionando el instrumento como autoreporte, existe todavía el hábito de querer entregar información falsa. Sin embargo, poco a poco se están dando cuenta que aparecen revisiones de cosas que ellos no declaran, por el aporte que tenemos de las bases de datos administrativas de otros organismos" (actor local, registro 1, 2017) 
Sin embargo, como señala el entrevistado 1, existe una percepción mayoritaria entre los usuarios, que la entrega de información falsa ha disminuido, lo anterior, sería producto del contraste de datos administrativos versus la declaración que efectúa el jefe de familia.

\section{Gráfico 2.}

Evolución de Entrega de Datos Falsos

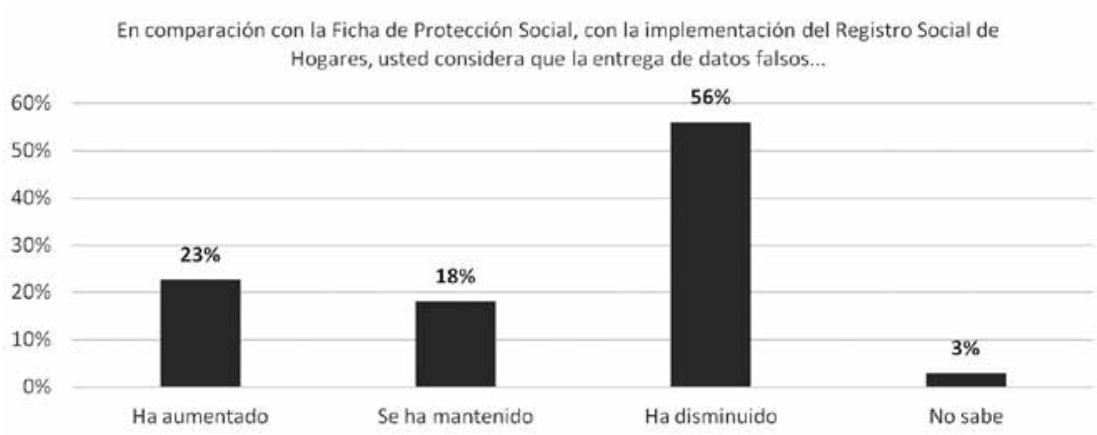

Esta percepción de los equipos comunales es concordante con los discursos de los entrevistados, quienes consideran que los datos administrativos que otorga el nuevo sistema de estratificación, ha permitido que disminuya esta conducta, sin embargo, los elementos que no son corroborados vía bases de datos administrativa, como la composición familiar, siguen siendo un elemento de tergiversación de información usado por las familias.

"la entrega de datos no fidedignos, no, yo creo que ha ido disminuyendo, paulatinamente ha ido disminuyendo, porque la gente, ehm, se va dando cuenta de que si ahora hay revisión, de hecho cuando ellos solicitan su cartola, aparecen ahí cuando hay información de base de datos que aceptaron sus resultados de tramo al cual calificación socioeconómica, a la cual pertenecen, ya.., de repente, dice ahí por ejemplo, la suma del avalúo de automóviles supera el límite máximo, y esto afectó su calificación socioeconómica" (actor local, registro 3, 2017) 
Los entrevistados concuerdan que la composición de la familia, es el elemento que mayormente sigue siendo manipulado para la obtención de beneficios sociales, apelando a diversas estrategias, como eliminar integrantes del grupo familiar, especialmente a los varones jefes de familia, o a las personas que poseen mayores ingresos o patrimonio. Al no existir barreras normativas para efectuar este procedimiento, los encargados comunales se ven sin herramientas para poder negar este tipo de cambios de estructura familiar.

"si tú quieres que yo sea franco, con respecto al autoreporte, cuando se refiere a desvincular personas, sí mienten, considerablemente, para efectos de beneficios sacan al marido, sacan al hijo, ya la gente manejó el instrumento" (actor local, registro 4, 2017)

Lo anterior, se corrobora en la Tabla 1, donde se evidencia que la segunda y tercera mayor solicitud que recibe la plataforma de parte de los usuarios, es la desvinculación o registro de nuevos integrantes. De la misma forma, el Gráfico 3, muestra que mayoritariamente los equipos comunales consideran que el RSH no logra evitar la modificación de composición familiar, luego de conocido el tramo de condición socioeconómica.

\section{Tabla 1.}

Solicitudes en el Registro Social de Hogares por tipo y periodo

\begin{tabular}{|c|c|c|c|c|c|c|c|c|}
\hline \multirow{3}{*}{$\begin{array}{l}\text { Solicitudes por tipo y periodo } \\
\text { Tipo de solicitud }\end{array}$} & \multicolumn{4}{|c|}{2016} & \multicolumn{4}{|c|}{2017} \\
\hline & \multicolumn{2}{|c|}{ 1er semestre } & \multicolumn{2}{|c|}{ 2do semestre } & \multicolumn{2}{|c|}{ 1er semestre } & \multicolumn{2}{|c|}{ 2do semestre } \\
\hline & $\mathbf{N}^{\circ}$ & $\%$ & $\mathbf{N}^{\circ}$ & $\%$ & $\mathbf{N}^{\circ}$ & $\%$ & $\mathbf{N}^{\circ}$ & $\%$ \\
\hline Ingreso al registro & 324.069 & $24,4 \%$ & 232.028 & $28,6 \%$ & 248.049 & $29,6 \%$ & 255.089 & $30,3 \%$ \\
\hline Cambio de domicilio & 116.022 & $8,7 \%$ & 59.525 & $7,3 \%$ & 62.274 & $7,4 \%$ & 61.709 & $7,3 \%$ \\
\hline Nuevo integrante & 239.354 & $18,0 \%$ & 147.522 & $18,2 \%$ & 147.792 & $17,6 \%$ & 152.052 & $18,1 \%$ \\
\hline Desvinculación integrante & 281.913 & $21,2 \%$ & 153.549 & $18,9 \%$ & 150.596 & $18,0 \%$ & 130.204 & $15,5 \%$ \\
\hline Actualización de módulo de salud & 34.889 & $2,6 \%$ & 20.445 & $2,5 \%$ & 15.452 & $1,8 \%$ & 15.955 & $1,9 \%$ \\
\hline Act. de módulo de educación & 27.065 & $2,0 \%$ & 14.662 & $1,8 \%$ & 11.920 & $1,4 \%$ & 13.214 & $1,6 \%$ \\
\hline Act. de módulo de vivienda & 177.400 & $13,3 \%$ & 80.989 & $10,0 \%$ & 77.544 & $9,3 \%$ & 75.236 & $8,9 \%$ \\
\hline Act. de ingresos monetarios & 109.765 & $8,3 \%$ & 54.316 & $6,7 \%$ & 65.786 & $7,8 \%$ & 72.446 & $8,6 \%$ \\
\hline Cambio de parentesco & 11.575 & $0,9 \%$ & 17.769 & $2,2 \%$ & 19.128 & $2,3 \%$ & 19.481 & $2,3 \%$ \\
\hline Act. de ingresos de trabajador dependiente & 0 & $0,0 \%$ & 13.113 & $1,6 \%$ & 17.490 & $2,1 \%$ & 20.282 & $2,4 \%$ \\
\hline Act. de ingr. de trabajador independiente & 0 & $0,0 \%$ & 604 & $0,1 \%$ & 1.003 & $0,1 \%$ & 1.300 & $0,2 \%$ \\
\hline Act. de ingr. de trabajador de capital & 0 & $0,0 \%$ & 607 & $0,1 \%$ & 637 & $0,1 \%$ & 977 & $0,1 \%$ \\
\hline Otras solicitudes & 7.036 & $0,5 \%$ & 16.166 & $2,0 \%$ & 20.558 & $2,5 \%$ & 22.987 & $2,7 \%$ \\
\hline Total de solicitudes & 1.329 .088 & $100 \%$ & 811.295 & $100 \%$ & 838.229 & $100 \%$ & 840.932 & $100 \%$ \\
\hline
\end{tabular}

Fuente: Ministerio de Desarrollo Social 2018 


\section{Gráfico 3.}

Modificaciones de declaraciones después de conocer el tramo.

¿que tan de acuerdo está con la siguiente afirmación? El RSH disminuyó la cantidad de personas que solicitan modificaciones a su declaración, luego que obtienen su tramo

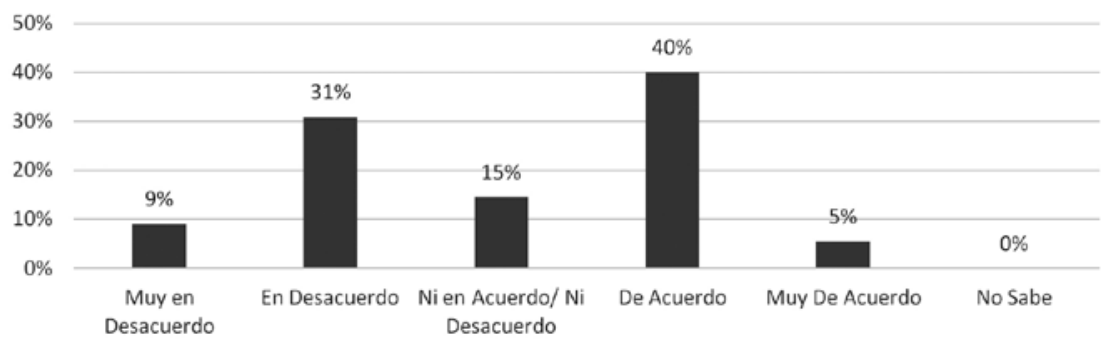

Fuente: Encuesta a encargados comunales del Registro Social de Hogares

Al ser consultados los encargados comunales, respecto a las justificaciones que tendría esta conducta en los usuarios, mayoritariamente se inclina por el deseo de aprovechar los beneficios que otorga la política social.

\section{Gráfico 4.}

Motivación de Conducta de Entrega de Información Falsa

En caso, usted considere que las personas entregan información falsa, ¿Cual es la principal motivación para desarrollar esta conducta?

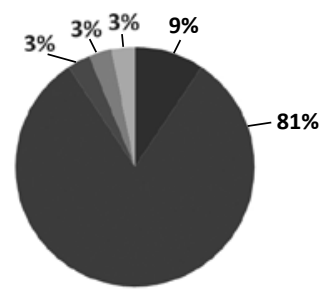


Los actores de la investigación, concuerdan que la búsqueda de beneficios sociales sería la gran motivación para la entrega de información falsa, y ésta sería la excusa para la entrega de información tergiversada, especialmente para aquellos beneficios sociales más sensibles como las becas de estudios para los hijos.

«Entrevistador: ¿cuáles son las mayores motivaciones para mentir? Entrevistada: Para obtener beneficios del Estado, sobretodo de la clase media, que son a quienes más les perjudica. Todo lo que es beneficio para jóvenes, para las familias, la gente manipula la información, o sacan los maridos, los jefes de hogar, eso es lo que sucede, porque igual, para obtener beneficios" (actor local, registro 5, 2017)

Frente a la interrogante de la entrega de información falsa, se les consultó a los equipos comunales, respecto a la percepción que poseen sobre el sexo de las jefaturas de hogar, que presentan mayoritariamente esta conducta, y un $94 \%$ considera que son las jefaturas de familia de sexo femenino, son las que mayormente entregan información tergiversada al sistema.

\section{Gráfico 5.}

Sexo de Informante que Entrega Información Falsa

En caso usted considere que los usuarios entregan información falsa al sistema. ¿Cual es el sexo de las Jefaturas de Familia que desarrollan esta conducta?

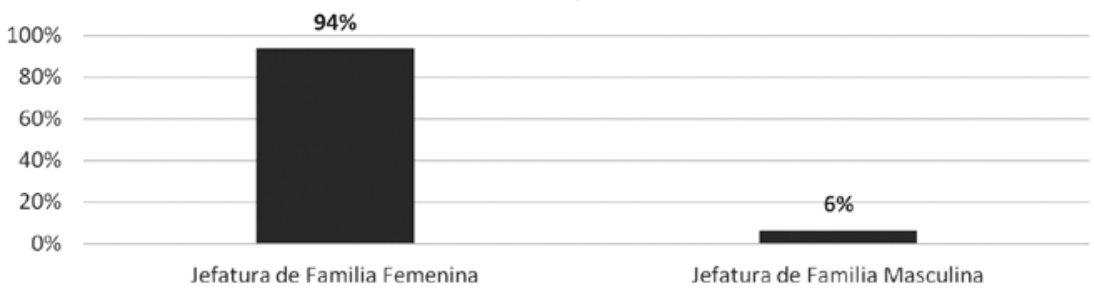

Fuente: Encuesta a encargados comunales del Registro Social de Hogares

- Sanciones

Respecto a las sanciones que pudieran recibir las familias que entreguen maliciosamente información tergiversada al sistema para obtener beneficios sociales, la Ley 20.379 establece una sanción pecuniaria de hasta 20 UTM 
aplicada por los juzgados de policía local, existiendo una plataforma ciudadana, para que cualquier persona pueda efectuar una denuncia (http://www.registrosocial.gob.cl/solicitud-supervision/) o de forma directa en dichos tribunales.

En base a lo anterior, se les consultó a los equipos comunales sobre las sanciones que reciben las personas que entregan información falsa al sistema, y no existe una visión uniforme entre los encuestados, destacándose que un $24 \%$ no sabe o no responde, lo que concuerda con los discursos de los entrevistados, quienes señalan que desconocen la existencia de sanciones y a la vez, no hay campañas publicitarias que inciten a evitar este tipo de conductas.

\section{Gráfico 6.}

Sanciones a Personas que Entregan Información Falsa

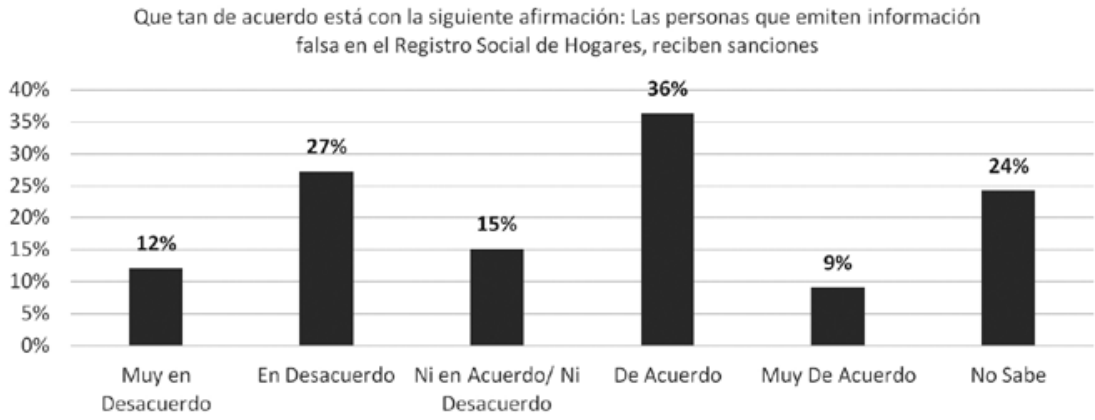

Fuente: Encuesta a encargados comunales del Registro Social de Hogares

Al revisar el Gráfico 6, se observa una leve tendencia en sostener que existen sanciones (45\%), sin embargo, los entrevistados consideran que las denuncias no tienen sanciones, existiendo un procedimiento en el Ministerio de Desarrollo Social para efectuar supervisiones, pero en ninguno de los relatos se evidencia alguna consecuencia de sanción.

«Entrevistador: Ahora, ¿cómo consideras que el Ministerio aplica sanciones, a quienes entregan información falsa, en la declaración del registro social de hogares? Entrevistada: Mira, nosotros con el único caso que hemos tenido, que finalmente, fue una señora que hizo una denuncia, no hemos tenido ningún tipo de sanción». (actor local, registro 2, 2017) 
«Entrevistador: ¿Qué grado de denuncias y sanciones existen, a casi 2 años de implementado el nuevo sistema? Entrevistada: Hm, por lo menos en mi comuna no, ninguna» (actor local, registro 3, 2017)

Por otra parte, destacan discursos en esta categoría, respecto a la poca difusión que desarrolla el Ministerio de Desarrollo Social -a modo de disuasión- de las sanciones que pueden recibir las personas que entreguen información falsa, y las consecuencias de mentir en la entrega de información.

Se considera que, la facultad de fiscalización exclusiva del Ministerio de Desarrollo Social resta capacidades a los municipios, y cuando los equipos efectúan denuncias al Ministerio frente a casos detectados y vulneraciones evidentes, no se conocen sanciones a dichas familias. Cabe señalar, que en el marco de la investigación se solicitó información al Ministerio de Desarrollo Social, respecto al número de denuncias judicializadas durante los años 2016 y 2017, y se indica que a la fecha (diciembre de 2017), no existen casos denunciados.

«Entrevistada: Lo importante es que el Ministerio informe a las personas, que si entregan información falsa van a ser sancionados, que a eso le pongan destacador, porque la gente como es muy liviana en entregar información, "me separe", por ejemplo, y traen el documento de que están anulados, que sé yo, pero no le toman el peso, porque digamos, ellos están obteniendo beneficios del Estado, entonces como que lo toman muy liviano". (actor local, registro 5, 2017)

Como no se evidencian sanciones a las personas que mienten, y los municipios no cuentan con capacidades sancionatorias, se tiende a desincentivar las denuncias de parte de los equipos comunales, tendiendo a aceptar la conducta de entrega de información falsa. Los protocolos del Registro Social de Hogares no le otorgan la capacidad de cuestionar las declaraciones de las familias, por ende, han tendido a dejar de cuestionarse frente a la entrega de información falsa y aceptarla. 


\section{Gráfico 7.}

Fiscalización sobre encuestas RSH aplicadas

Que tan de acuerdo está con la siguiente afirmación: El Ministerio de Desarrollo Social, ha aumentado las fiscalizaciones sobre encuestas aplicadas

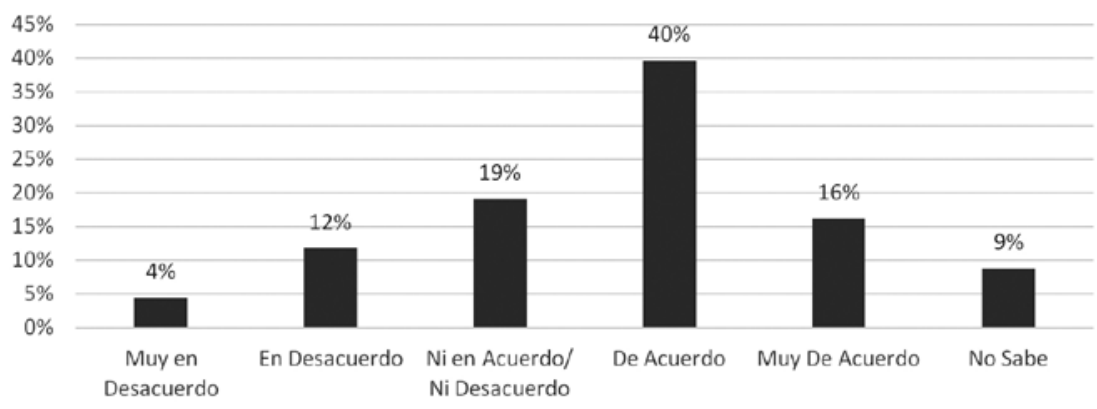

Fuente: Encuesta a encargados comunales del Registro Social de Hogares

Aun así, los discursos evidencian un aumento en las supervisiones que efectúa el Ministerio de Desarrollo Social a los equipos comunales, a partir de la incorporación de supervisores en las provincias, quienes efectúan revisión de los procesos comunales, apoyo y acompañamiento en los casos que el municipio requiere supervisiones, sin embargo, no destacan discursos sobre el aumento de supervisiones a familias que pudieran entregar información falsa.

"las supervisiones que son más constantes, desde la SEREMIA, también creo que eso nos facilita harto el trabajo, la comunicación que tenemos con ellos también, que nos permite ir resolviendo las cosas un poco más rápido, la mesa de ayuda, funciona, se demora, pero funciona (se ríe)" (actor local, registro 2, 2017)

Finalmente, se puede concluir que existen sanciones establecidas en la propia ley, para las personas que entreguen información falsa al sistema, sin embargo, el Ministerio de Desarrollo Social no ha requerido dichas sanciones ni ha generado campañas publicitarias tendientes a disminuir la conducta. A su vez se evidencia que los municipios han perdido una capacidad sancionatoria en este tema y han tendido a normalizar la conducta de los usuarios al no poseer herramientas disuasivas en el tema. 


\subsection{PERCEPCIÓN A LAS PRINCIPALES MODIFICACIONES DEL RSH}

La segunda categoría, corresponde a un análisis desarrollado desde la percepción de los actores comunales, que buscó explorar las principales modificaciones que se evidencian entre la antigua Ficha de Protección Social y el nuevo Registro Social de Hogares. En primer lugar, se destaca como un hallazgo, la confiabilidad de información recibida, especialmente aquella relativa a ingresos, discapacidad y educación; por el contrario, y de acuerdo al Gráfico 9, se evidencia que el área con menor confiabilidad es la situación de autoreporte de los integrantes del grupo familiar, lo que concuerda con los datos analizados anteriormente.

\section{Gráfico 8.}

Confiabilidad de Información de RSH

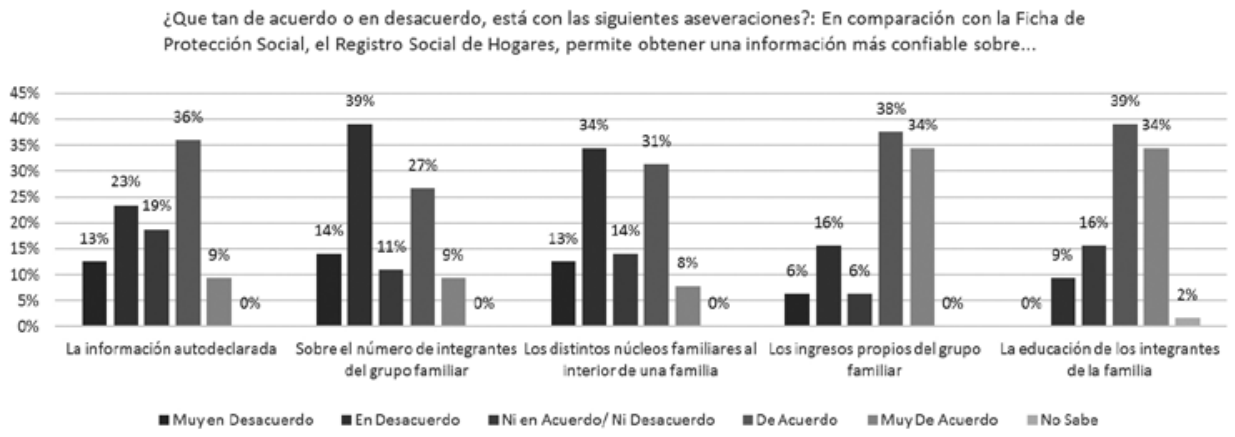

Fuente: Encuesta a encargados comunales del Registro Social de Hogares

Los ítems que evidencian mayor confiabilidad son los ingresos, educación y discapacidad, siendo estos módulos en el RSH, los que mayormente cruzan información con bases de datos administrativas de los servicios de impuestos internos, ministerio de educación, registro civil, etc. 


\section{Gráfico 9.}

Confiabilidad de Información de RSH

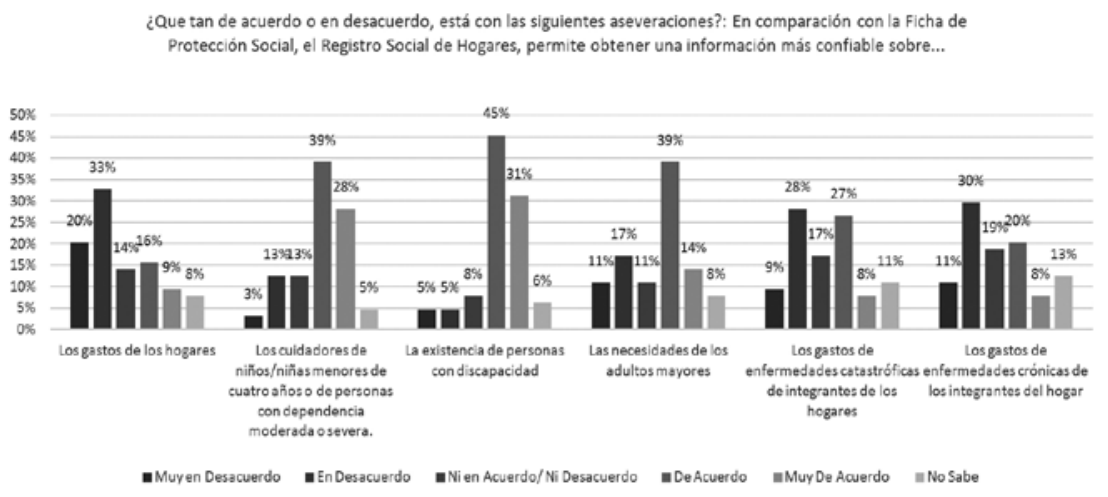

Fuente: Encuesta a encargados comunales del Registro Social de Hogares

a) Gastos Familiares

Un segundo elemento que se evidencia como falta de confiabilidad en la información corresponde a los gastos familiares, ya que, es un ítem que sigue sin ser consultado en los instrumentos, a pesar de ser diagnosticado como un elemento necesario, de acuerdo al Informe del Comité de Expertos de FPS.

"Debiera considerarse (lo gastos), y además que yo creo que es injusto, porque a veces hay gente que, y sobretodo casi siempre, los mismos pensionados, que casi se les va la plata toda en remedios, pagas luz, agua, y quedas mirando, debieran considerarse, porque hay gente que tiene hijos con enfermedades que gastan diariamente, ¿cuánta plata se les va?, ahora, debieran considerar el líquido a pagar, porque a fin de cuentas, con eso tú te das cuenta que con eso se dan vuelta, con eso tú comes, con eso tú pagas arriendo, con eso tú estudias, todo; lo otro no debiera ser, porque claro es a favor tuyo, pero no lo ocupo yo en el instante, hay gente que tiene no sé, 1 millón de pesos en total de haberes, y en el pago tiene 600, 700 lucas, son 300 lucas de más, que no es la realidad” (actor local, registro 4, 2017) 
Los discursos entregados en las entrevistas, concuerdan con la necesidad de considerar los gastos en el cálculo de los tramos del RSH, especialmente aquellos relativos a enfermedades o situaciones de discapacidad, sin embargo, este ítem sigue usando el patrón de datos de la antigua FPS, y sólo considera las condiciones de dependencia. El RSH no considera los gastos que posee una familia en cuanto a arriendo, luz, agua, gas u otros senvicios básicos, todos ellos se asumen parte del consumo de un grupo familiar, y el único gasto que se considerado como rebaja de los ingresos de una persona, son los pagos por pensiones de alimentos.

"Gastos, así como cotidianos, luz, gas, arriendo, agua, no; ... si da una opción de actualizar para la gente que paga pensión de alimentos, ponte tú un papá que paga 50 mil pesos por un hijo, y esta decretado por una mediación, ratificado por el tribunal, se hace una actualización, donde a él se le incorpora de que él paga cierto monto, por pensión de alimentos, o sea, eso se le carga al hogar de la otra familia" (actor local, registro 6, 2017)

Al asociar los gastos de los integrantes del grupo familiar a enfermedades, la situación no sufre diferencia, sin embargo, existen relatos que señalan la necesidad de considerar los ingresos, descontados los gastos producidos por enfermedades catastróficas. Hasta ahora, solo se puede eliminar del test de medios, el complemento de ISAPRE por situaciones de gastos provocado por enfermedades catastróficas, pero no se considera el valor de los gastos de medicamentos, tratamientos y otros asociados a este tipo de situaciones. Cabe señalar que desde el año 2016 se implementó en Chile la Ley 20.850, denominada «Ricarte Soto", que establece un sistema de registro de personas con enfermedades catastróficas y un aporte a los gastos en medicamentos asociado a este tipo de enfermedades, por ende, el dato administrativo está a disposición del Estado.

"Asociado a eso, va el tema de las ISAPRES, tenemos casos en que las familias están afiliadas a ISAPRE por temas de salud, y las ISAPRES se consideran dentro de la calificación como complemento, si es por enfermedad catastrófica, da la posibilidad de ingresar una actualización, donde tú presentas el certificado médico, más una declaración, donde tú informas, que por tal enfermedad, tú obligatoriamente, debes estar afiliado a esa ISAPRE, entonces, eso hace que se borre ese complemento, para que la calificación no sea tan alta; pero, en temas de gastos, no hay nada relacionado a esto, si sería bueno, si sería importante considerarlo, porque hay mucha gente que gasta mucho en salud» (actor local, registro 6, 2017) 


\section{b) Ingresos}

En comparación con la Ficha de Protección Social, el RSH permite obtener una información más confiable sobre los ingresos del grupo familiar, el cual, como indican los manuales del Ministerio de Desarrollo Social (2016), cruza la información de ingresos mediante el Rut del integrante familiar, contra las bases de datos administrativas, e informa los ingresos anuales reales de las personas. De esta forma, se obtienen los ingresos de todos los integrantes del grupo familiar para efectos de caracterización socioeconómica. Este mecanismo otorga mayor confiabilidad de la información, ya que la antigua Ficha de Protección Social sólo considera el ingreso que autoreportaba la familia, sin embargo, el nuevo RSH mantiene el autoreporte, pero luego es contrastado con la información que arroja el Servicio de Impuestos Internos y otras bases de datos administrativas.

Este cruce de información es considerado por los actores de la investigación, como uno de los más eficaz por la veracidad de los datos, sin embargo, es ineficiente, pues la actualización de la información de la Base del Servicio de Impuestos Internos tiene un retraso entre 3 meses a 1 año, lo que dificultaría una información veraz de forma rápida. Ejemplo de lo anterior, lo constituyen los finiquitos, las quiebras o los ingresos de capital. La información no se actualiza de forma inmediata, restando meses para que sea verificada en el RSH y se refleje en la Caracterización Socioeconómica de la familia.

Este desfase en la información, frente al requerimiento del usuario, puede ser regularizada por los municipios, y un proceso de rectificación en el sistema, que se acredita con documentos entregados por la persona afectada. De esta forma, se quita la presión sobre los equipos comunales, frente a requerimientos oportunos de actualización de información de ingreso familiar.

"hoy en día, en eso es más lento, mucho más lento, por la actualización de la base de datos del Servicio de Impuestos Internos, podemos demorar 3, 4 meses, hasta 1 año, dependiendo del trámite que venga a hacer la persona" (actor local, registro 2, 2017)

Las fuentes de información que entrega la base de datos del SII consideran los ingresos del trabajo, ya sea en primera o segunda categoría, es decir, considera los ingresos de remuneraciones, honorarios y rentas obtenidas de capital, por ende, esta información es clave a la hora de efectuar la caracterización socioeconómica de la familia, pues recoge todas las opciones tributarias que poseen las personas en Chile. 
"lo que pasa es que hay 3 tipos de ingresos, ya, ingreso por el trabajo, ingreso por pensiones e ingresos por el capital, entonces todo lo que tiene que ver con declaraciones de impuesto, que es lo que tú me mencionas, no sé si tiene un boliche, un almacén, si tiene alguna cosa donde tiene que hacer su declaración, por ahí se sacan los ingresos y lo reporta impuestos internos a nosotros". (actor local, registro 1, 2017)

"yo creo que quizás el obstáculo mayor, es que la gente siempre quiere una respuesta rápida, (...) hay bases de datos que son anuales, por ejemplo, la de renta, la declaración de renta; nosotros, en este instante, todavía no nos llega la del 2016, de impuestos internos, por lo tanto, lo que hay de renta es del 2015, ya, se supone que en el mes de octubre debiera llegar, y en noviembre ya deberíamos estar operando" (actor local, registro 1, 2017)

A pesar de la confiabilidad de los datos de ingresos de las personas, mediante sus RUTs, se identifica un grupo de población que no puede contrarrestar información y son aquellos que no cotizan, ni poseen información en los sistemas de impositivos, ya sea por trabajos de forma irregular (sin contratos) o el caso de inmigrantes que no poseen residencia ni visa de trabajo.

"claro, hay gente que a lo mejor si puede mentir y que no hay de donde sacarle ingresos, porque nunca ha cotizado, nunca tuvieron iniciación de actividades, pero son los menos, son los menos" (actor local, registro 6, 2017)

En estos casos, el sistema tomaría la información autodeclarada por el informante del grupo familiar, sin capacidad de contrarrestar la información, asumiendo acá la posibilidad de tergiversar o falsear datos en el sistema.

\section{c) Discapacidad/Dependencia}

Otro elemento que destaca por su nivel de confiabilidad, es la información de cuidadores de niños menores de cuatro años, personas con discapacidad y las necesidades de los adultos mayores, considerada esta información como autodeclarada en el cuestionario aplicado. Esta información es contrastada contra la base de datos del Registro Civil respecto al Registro Nacional de Personas con Discapacidad y los grados de discapacidad que se encuentran acreditados en la Comisión Médica Preventiva e Invalidez COMPIN, y se conserva la estructura de preguntas que tenía la FPS respecto a niveles de dependencia. 
"tenemos las mismas preguntas de dependencia, que son las 6 preguntas para saber si hay alguna situación de salud de carácter permanente" (actor local, registro 1, 2017)

"tenemos lo que es la vulnerabilidad, que es la dependencia de la persona, cuando las personas son más dependientes, son más vulnerables, es decir, es más difícil que se autosustente, cierto, tenemos los niños, los adultos mayores, personas con discapacidad, ellos son y eso aumenta el denominador" (actor local, registro 1, 2017)

Los ítems de dependencia severa del grupo familiar, son contrastados con bases de datos administrativas de la COMPIN, y de acuerdo a los porcentajes de discapacidad que se encuentren registrados y acreditados, será la influencia que tenga en el Índice de Necesidades del grupo familiar.

"Yo creo que ahora se está ordenando el tema, porque también hoy día hay cruce con el tema de salud, discapacidad, y todo lo demás, el Ministerio te exige el documento, por ejemplo, cuando nosotros le pedimos la tarjeta de COMPIN, la tarjetita que tiene discapacidad, ahí lo dice altiro" (actor local, registro 4, 2017)

A pesar de ser una información autodeclarada, se observa cierto desconocimiento en los actores entrevistados respecto a requisitos y cruce de información de base de datos del Registro Civil. En un caso, se estaría requiriendo comprobar las condiciones de discapacidad mediante la presentación de la credencial nacional de discapacidad que entrega el Registro Civil e Identificación, a pesar de no ser exigidas en los manuales del Ministerio de Desarrollo Social, ya que la información se cruza de forma interna en el sistema.

«Entrevistada: la gente asocia las enfermedades como que se las debemos ingresar, pero no entienden que va asociado a un tema de dependencia, entonces uno les tiene que explicar, y si la persona insiste mucho, se le hace la actualización, pero la dependencia queda en 0 , entonces no le va a incidir en el tema de la calificación, y si no me equivoco, también está en línea con el tema de la discapacidad, como está en línea con el Registro Civil, la gente que tiene acreditada su discapacidad ante el Registro Civil, se le refleja, y tiene que estar acreditado si o si, estar inscritos en el Registro Civil, es lo ideal. Entrevistador: Y, ¿si no están inscritos? Entrevistada: 
Ahí no estoy segura como opera, si es que pasa a operar con lo que ellos autodeclaran, me imagino que sí, pero yo creo que esa se ha mantenido, la gente siempre va a mentir en esos temas que son autoreporte" (actor local, registro 3, 2017)

Otro elemento que se destaca en el análisis documental sobre discapacidad, es que el Manual del Ministerio de Desarrollo Social establece que, en caso de presencia de personas postradas o discapacitadas, el Registro Social de Hogares no considera dentro del patrimonio familiar el vehículo de mayor tasación, a modo de no afectar el patrimonio de la familia y considerar de mejor forma la situación de dependencia en el cálculo de tramos.

\section{Gráfico 10.}

Actualización de Bases de Datos

De les siguientes bases de datos del Registro Social de Hogares, ¿Cuáles considera actualizan datos de forma más frecuente?

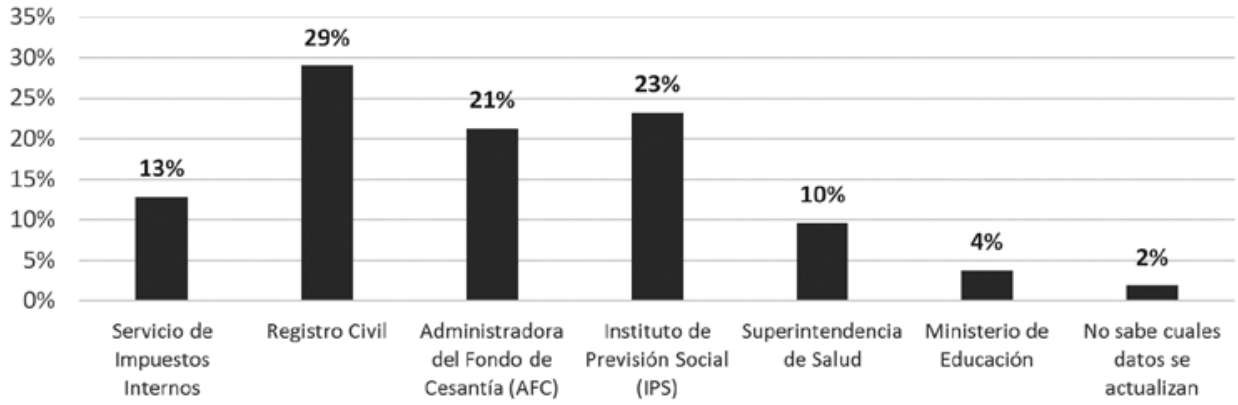

Fuente: Encuesta a encargados comunales del Registro Social de Hogares 


\section{d) Educación}

Finalmente, sobre confiabilidad de la información, para los equipos comunales el módulo de educación es uno de los que representa mayor confianza, pues se identifica un cruce de datos con bases del Ministerio de Educación, sin embargo, es la base que posee una menor frecuencia de actualización en comparación con las demás bases de datos del Registro Social de Hogares.

«En el tema educacional, nopo, aparte que es autoreporte, nada más, en algún momento se cruza, será 1 vez al año con el Ministerio" (actor local, registro 3 , 2017)

A pesar de lo anterior, se reconoce como una mejora sustantiva entre el antiguo instrumento y el nuevo Registro Social de Hogares, ya que entrega una información fidedigna de los niveles educacionales, y a la vez, es una fuente de información respecto al pago de colegiaturas en colegios particulares pagados, dato utilizado para el test de medios, como un mecanismo de ingresos de la familia.

"Respecto a la educación de los integrantes de la familia..., se sabe mucho más ahora porque, de hecho, nosotros dentro de las preguntas de educación se pregunta, si una persona está estudiando y si la respuesta es sí, no se hacen más preguntas, porque se consulta al mes siguiente en la base- del Ministerio de Educación, y ahí nos dice dónde está estudiando, qué está estudiando, cuál es el pago de la colegiatura de lo que está estudiando"(actor local, registro 1, 2017)

De esta forma se reconoce un avance respecto a información de educación, la cual era una variable importante en cálculo de la antigua Ficha de Protección Social, sin embargo, se critica la ineficiencia en la actualización de las bases de datos.

\subsection{CALCULO DE TRAMOS}

Finalmente, se les consultó a los equipos comunales, su visión respecto a los principales cambios del sistema de puntajes asignados a las familias, versus el sistema de tramos que otorga el Registro Social de Hogares. Para evaluar este item, se analizaron las encuestas comparando las respuestas de funcionarios que habían trabajado con FPS, que se denominará grupo 1 y los que no habían trabajado con FPS y sólo tienen la experiencia con el nuevo instrumento que se denominará grupo 2 . 


\section{Gráfico 11.}

Situaciones que afectan la Condición Socioeconómica CSE

El RSH, ¿en que grado considera para el cálculo de tramos, las siguientes situaciones?

(Grupo 1)

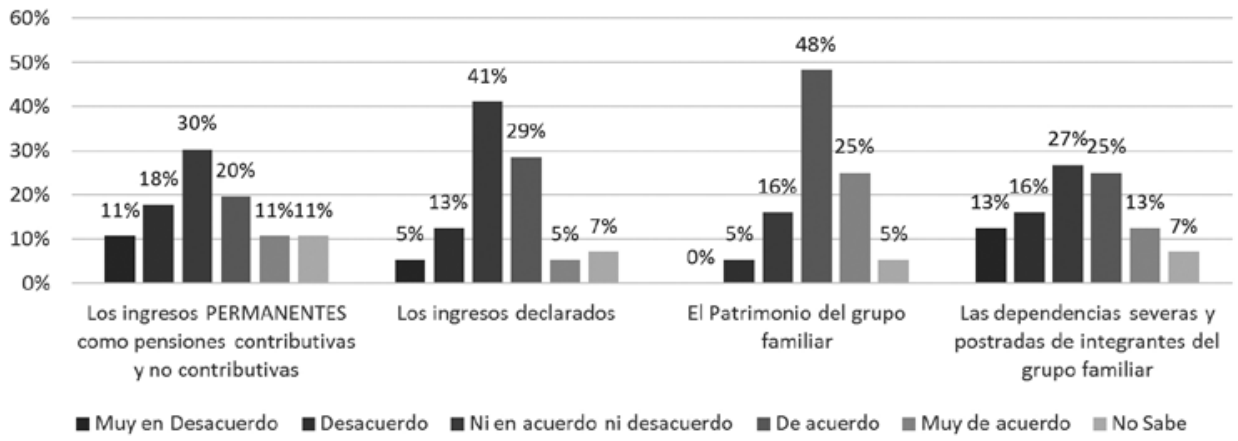

Fuente: Encuesta a encargados comunales del Registro Social de Hogares

Gráfico 12.

Situaciones que afectan la Condición Socioeconómica CSE

El RSH, ¿en que grado considera para el cálculo de tramos, las siguientes situaciones?

(Grupo 2)

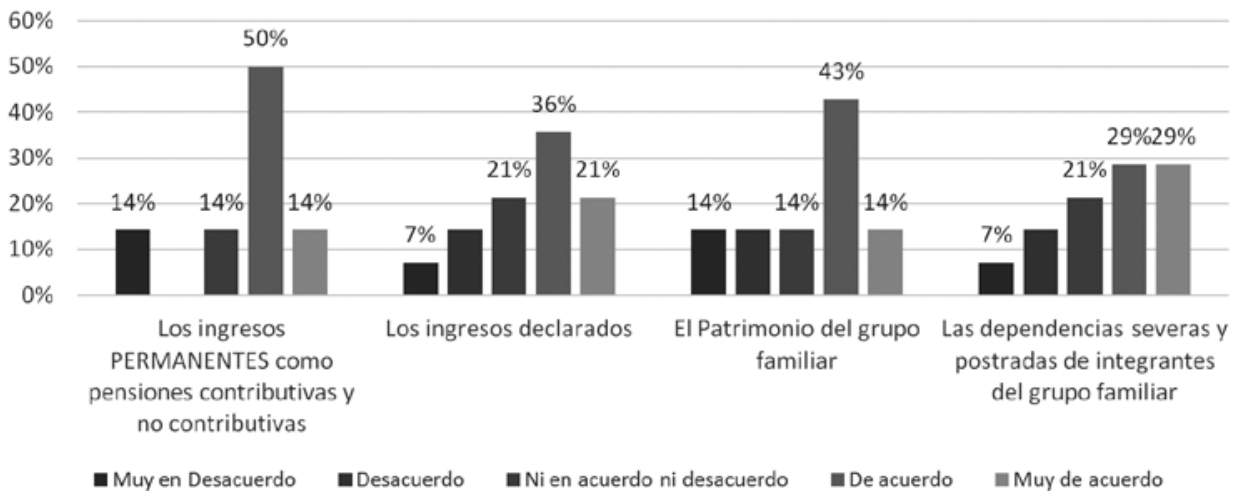

Fuente: Encuesta a encargados comunales del Registro Social de Hogares 
En este ejercicio comparativo, uno de los principales hallazgos en el cálculo de tramos, es la diferencia de opinión respecto a la importancia de las pensiones como ingresos permanentes, donde el grupo 1 le otorga una menor valoración que el grupo 2. Lo anterior, se explicaría en base a la relevancia que tenía en el cálculo del puntaje FPS la presencia de ingresos permanentes como las Pensiones Básicas Solidarias o las pensiones de trabajo, las cuales hacían subir considerablemente el puntaje asignado. El Registro Social de Hogares, considera de forma importante los ingresos, pero aquellos informados en bases de datos oficiales, perdiendo peso y relevancia el ingreso declarado, el cual, sólo se considera en caso no exista un registro administrativo asociado al RUT.

"Ponte tú, antes, las mamás solteras que ocultaban a sus maridos, tenían 2 mil puntos, pero hoy en día, algunas de esas mamás trabajan, entonces ahora se les ven sus ingresos, y puede que no estén en los tramos más bajos, y puede que estén dentro de los 3 , pero a lo mejor no en el $40 \%$, entonces si se ha equiparado con el tema del tramo, a mí me gusta más ahora, que antes" (actor local, registro 6, 2017)

Ambos grupos consideran como un elemento relevante en el cálculo de tramos, la variable patrimonio, la que considera activos asociados a los RUT de los integrantes del grupo familiar, los cuales constituyen un análisis denominado "test de medios", el que observa los ingresos y el acceso a bienes y servicios.

Los bienes y servicios considerados en dicho test son (Ministerio de Desarrollo Social, 2016a):

1) El valor total de el/los vehículos que son propiedad de los integrantes del hogar. Para ello se considera el valor de avalúo fiscal definido por el Servicio de Impuestos Internos (SII).

2) El valor total de el/los bienes raíces que son propiedad de los integrantes del hogar. Para ello se considera el valor de avalúo fiscal definido por el Servicio de Impuestos Internos (SII).

3) El valor de la mensualidad del establecimiento educacional en el que están matriculados uno o más integrantes del hogar (pre-escolar, básica y media). 4) El valor de las cotizaciones de salud pactadas con la institución de salud. 
De esta forma, el patrimonio de bienes y acceso a servicios, se suma a los ingresos que posee el grupo familiar y se ajusta este Test de Medios contra con las necesidades del grupo familiar, resultando la clasificación en alguno de estos tramos socioeconómicos.

«Puede que una familia esté en un tramo socioeconómico bajo, pero nosotros por ejemplo, podemos decir, «pero, cómo tiene vehículo?, la familia puede tener propiedades, entonces el sistema le fija un test de medios, es decir, te evalúa a través de Impuestos Internos, si tienes un vehículo de alto valor, si tienen propiedades de alto valor, si la familia está en ISAPRE o con un alto valor; entonces, te permite también, aplicar este test de medios a esas familias, y te va a decir, «no, esta familia no está en el $40 \%$, va a estar en el 70 , o en el $80 \%$ (actor local, registro 5, 2017)

Respecto de situaciones de riesgo social o vulnerabilidad que influyen en la clasificación en algunos de los tramos socioeconómicos, ambos grupos concuerdan que la presencia de personas con dependencia severa o postradas, sus cuidadores y aquellos que fungen como cuidadores de niños y niñas, afectan este índice. Sin embargo, se observa una diferencia entre ambos grupos al consultar por la presencia de Adultos Mayores en la familia, donde el grupo con mayor experiencia considera que esta variable no influye de la misma forma para el cálculo de tramos. Lo anterior se explicaría por la influencia que tenía la presencia de adultos mayores en el hogar, al momento de calcular el puntaje de Ficha de Protección Social, situación que el registro social de hogares tiende a considerar en menor relevancia para la clasificación socioeconómica de las familias. 


\section{Gráfico 13.}

Situaciones que afectan la Condición Socioeconómica CSE

El RSH, ¿en que grado considera para el cálculo de tramos, las siguientes situaciones?

(Grupo 1)

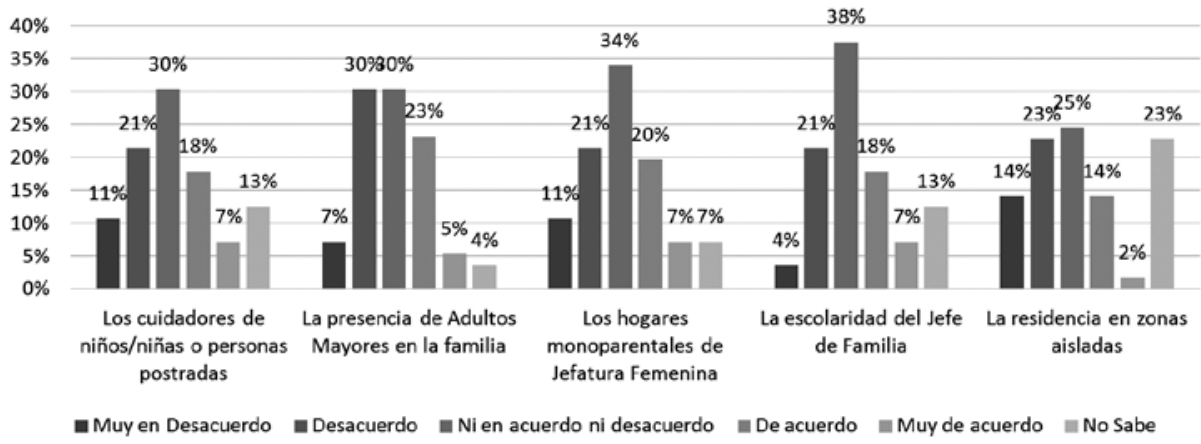

Fuente: Encuesta a encargados comunales del Registro Social de Hogares

Gráfico 14.

Situaciones que afectan la Condición Socioeconómica CSE

El RSH, ¿en que grado considera para el cálculo de tramos, las siguientes situaciones?

(Grupo 2)

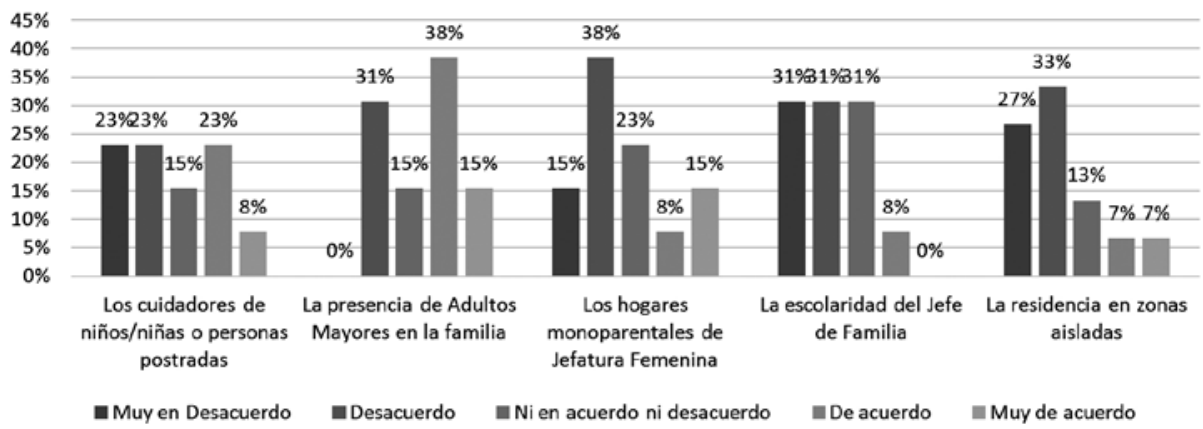

Fuente: Encuesta a encargados comunales del Registro Social de Hogares 
En el caso de los hogares monoparentales, que era otra variable que afectaba el puntaje de la Ficha de Protección Social, ambos grupos coinciden la baja influencia de esta condición en el cálculo del tramo socioeconómico de la familia, de la misma forma, la condiciónde baja escolaridad del jefe de familia no estaría influyendo considerablemente en la forma de clasificación de la familia en la condición socioeconómica.

«Entrevistador: En cuanto a la educación de los integrantes de la familia, la información real, ¿ha disminuido, ha aumentado, se ha mantenido? Entrevistada: Yo creo que se ha mantenido, o sea, como te digo, la gente todavía tiende a pensar que la escolaridad hace que el tramo te aumente,pero, además la escolaridad también está en línea con el Ministerio de Educación, en el caso de las personas que estudian, el Ministerio arroja información de qué curso están» (actor local, registro 6, 2017)

Finalmente, un ítem que fue revisado en el Informe de la Comisión de Expertos FPS, fue la condición de vivir en territorios aislados o alejados de centros urbanos, situación que, de acuerdo a los equipos comunales, no tendría un efecto en el cálculo del tramo socioeconómico.

De esta forma se evidencia por parte de los equipos comunales, que el cálculo de tramos privilegia las condiciones materiales y de servicios más que las condiciones de vulnerabilidad, tales como infancia, adulto mayor, personas discapacitadas, hogares monoparentales de jefatura femenina, etc. De esta forma, la focalización por tramos, se concentra mayoritariamente en la visión de carencia material y de exclusión de familias que posean ingresos o patrimonios altos.

«antes en la ficha, era el tema de la vulnerabilidad, que la persona, pero aquí, pesan los ingresos, o sea, el que te evalúen un vehículo de un rango hacia arriba, el que te evalúen la vivienda, de un rango hacia arriba, que tenga 2 o 3, ¿qué te habla? de pobreza. El que te evalúe un programa de ISAPRE o FONASA ¿de qué te habla? Entrevistador: Pobreza, y, ¿eso tiene mayor peso que las condicionantes de adulto mayor por ejemplo? Entrevistada: Es que es eso, eso es, porque dicen que el modelo primero te gestiona, respecto al número de integrantes, los ingresos la nada, y las características de los integrantes, la edad, y las enfermedades, es prioridad, y después pasamos a lo otro, pero la edad y las enfermedades, si tenemos a una persona que no ve, y gana 500 lucas pero no tiene con qué vivir, igual va a estar en un tramo alto" (actor local, registro 3, 2017) 
«hay que tener en cuenta que son 2 mitades, el numerador y el denominador, y las 2 me pueden hacer subir o bajar mucho, entonces una mitad, el numerador son los ingresos, y, pero son los ingresos reales, por lo tanto, ahí estamos midiendo pobreza, y el denominador, el índice de necesidades, pero ahí estamos midiendo vulnerabilidad, por lo tanto yo diría que es una herramienta más equilibrada" (actor local, registro 1, 2017)

\subsection{CARTOLA HOGAR}

Finalmente, desde los discursos de los entrevistados se evidencian relatos positivos a los cambios entre el Registro Social de Hogares y lo que era la Ficha de Protección Social, evidenciando de forma positiva el cambio desde la forma de clasificación numérica que tenía el antiguo instrumento, al nuevo sistema de tramos, lo que según indican, es más sencillo y la utilización de la cartola hogar, mejora los procesos de transparencia y claridad para comprender la clasificación socioeconómica de la familia.

«Entrevistador: ¿Y, las personas cómo se comportaron en esta diferencia de tramos, puntajes, saben la diferencia? Entrevistada: No la entienden mucho de repente, "¿por qué dice 40 ?", porque a veces el sistema pide que estén en el 60 , o 50\%, y ellos a veces están, por ejemplo si te piden el 40, ellos te van a decir 51, o 41, y por 1 punto, no les permite, entonces nosotros les decimos, que no hay nada que hacer, porque esa es la calificación que emitió el sistema, en base a la información que ellos dan, y de lo que valida el sistema; entonces, ahí no hay nada que hacer, a menos que, siempre se revisa la cartola con la familia, y vamos actualizando la información" (actor local, registro 5, 2017)

Otra de las modificaciones que incorpora el RSH, es la entrega de la cartola hogar, la cual es el documento que resume la información con que cuenta el Registro Social de Hogares y que es utilizada para la construcción de la Calificación Socioeconómica de la familia. Esta cartola considera:

- Información del domicilio del hogar

- Integrantes del hogar

- Ingreso promedio mensual del hogar

- Tramo de Calificación Socioeconómica

- Datos complementarios que influyen en la calificación del hogar 
De esta forma, la familia conoce los elementos que fueron analizados para efectuar la clasificación, en alguno de los tramos de caracterización socioeconómica.

"Yo creo porque está más clara, una la transparencia porque en el certificado del puntaje de la ficha de protección social, salía el nombre, el RUT del solicitante, y su puntaje, y nada más pues, y eso para ellos era algo abstracto, en cambio ahora no, ahora en la cartola le sive a la gente para saber si sus datos están correctos o no, dentro del registro, porque sale el retrato completo, sale la identificación del solicitante, sale la identificación de todo el grupo familiar, sale el domicilio, salen los ingresos por trabajo, salen los ingresos por pensiones, los ingresos por capital, ehm ya, y la calificación socioeconómica" (actor local, registro 1, 2017)

«Entrevistador: Ya, la siguiente pregunta es, uno de los resultados del informe de expertos, decía que había un alto número de personas que una vez que se enteraban de su puntaje de la ficha de protección social, actualizaban en un corto periodo su ficha, ¿con la incorporación del registro social de hogares, esa conducta, disminuyó? Entrevistada: Disminuyó, se evidencia efectivamente, y ¿por qué?, porque saben, porque tú les explicas, o sea, el registro necesariamente implica más tiempo de atención al usuario, porque tienes que explicarle la cartola, "estos son sus ingresos, y provienen de aquí, acá, y allám... ha favorecido la transparencia, y que las personas se queden también, no te puedo decir más tranquila, pero existe algo objetivo que ellos puedan corroborar, porque es su información la que está plasmada ahín (actor local, registro 2, 2017)

De esta forma, se evidencia desde los entrevistados, lo relevante que se transformó esta innovación en el sistema, explicando al usuario las razones de su caracterización socioeconómica, lo que, según entrevistados ha disminuido los reclamos por parte de los usuarios, luego de obtenida su clasificación socioeconómica. 


\section{CONCLUSIONES}

La modificación del instrumento utilizado en Chile para efectuar políticas residuales, ha generado un cambio de perfil del beneficiario de la política social, privilegiando personas y familias con baja materialidad y restando relevancia a las variables de vulnerabilidad. Como principales conclusiones se evidencian relatos y percepciones positivas desde los actores locales que implementan el nuevo registro social de hogares en comparación a las deficiencias que tenía la Ficha de Protección Social como instrumento de focalización. A pesar de lo anterior, se evidencia que persiste la entrega de información falsa por parte de los usuarios del sistema, específicamente en la composición familiar y la declaración de ingresos, a su vez se identifica por parte de los actores que no existen sanciones para las personas que entregan información tergiversada, lo que desincentiva la denuncia por parte de los mismos equipos comunales.

Respecto a los mayores cambios que evidencian los actores del registro social de hogares, comparándolo con la Ficha de Protección Social, resalta en materia de tramificación, la importancia relativa que cobran las variables como el patrimonio y el ingreso, en el cálculo de la condición socioeconómica, y a su vez, se destaca la falta de consideración de los gastos por enfermedades catastróficas y consumos básicos. Se evidencia que sigue influyendo la variable discapacidad y/o dependencia en el cálculo del tramo. Finalmente, los actores consideran que las bases de datos de Educación y Servicio de Impuestos Internos son las más ineficientes en su proceso de actualización de información y que la nueva forma de entregar información a los ciudadanos, mediante la cartola hogar mejora el entendimiento de su condición socioeconómica.

Quedan como desafíos para seguir avanzando en la implementación de este instrumento en el país, evidenciar desde los servicios públicos que entregan las prestaciones sociales, ¿Cómo ha cambiado el perfil del beneficiario? Y si efectivamente se ha producido un cambio en torno a la materialidad y la carencia, versus la vulnerabilidad. 


\section{NOTA}

1 Trabajo fue presentado a la XIV Conferencia Anual INPAE (Red Latinoamericana de Enseñanza en Administración Pública) organizada por la Universidad de Guadalajara los días 14 al 18 de mayo de 2018, bajo el título "La selección de beneficiarios sociales en Chile como profundizador de brechas sociales. El caso del Registro Social de Hogares". El estudio fue financiado por proyecto VRID 217.058.007-1.0IN, y fondo de incentivo académico de la Facultad de Ciencias Jurídicas y Sociales, ambos de la Universidad de Concepción.

\section{BIBLIOGRAFÍA}

Azevedo, V., Bouillon, C., \& lararrazaval, I. (2011). Sistemas Integrados de Información Social: su rol en la protección social "Centro UC Políticas Públicas ( $1^{\text {a }}$ ed.). Santiago de Chile: Salesianos Impresores. Recuperado a partir de http://politicaspublicas.uc.cl/publicacion/ otras-publicaciones/sistemas-integrados-de-informacion-social-su-rol-en-la-proteccion-social/

Berner, H. (2016a). Registro social de hogares: el nuevo sistema chileno de apoyo a la selección de usuarios de prestaciones sociales. En XXI Congreso Internacional del CLAD sobre la Reforma del Estado y de la Administración Pública, Santiago, Chile, 8 - 11 nov. 2016. Santiago de Chile.

(2016b). Registro Social de Hogares: Sistema de Apoyo a la Selección de Usuarios de Prestaciones Sociales. Reemplazo de la Ficha de Protección Social. Presentado en Presentación a Parlamentarios y Gabinetes Regionales, Cámara de Diputados.

Bowles, S., Durlauf, S.N., \& Hoff, K. (2016). Poverty Traps (Edición: Reprint). Princeton, NJ: Princeton University Press.

Candia, A., \& Henoch, P. (2017). Reemplazo a la Ficha de Protección Social: definiciones y primeros resultados del nuevo instrumento de focalización. Serie Informe Social. Libertad y Desarrollo, 164, 23.

Coady, D., Grosh, M.E., \& Hoddinott, J. (2004). Targeting of transfers in developing countries: review of lessons and experience. Washington, D.C: World Bank.

Contraloría General de la República (2015). Informe de Investigación Especial 15-14 Ministerio De Desarrollo Social Sobre Nueva Ficha De Protección Social - Febrero 2015. Santiago, Chile: CGR. Recuperado a partir de http://www.contraloria.cl/SicaProd/SICAv3-BI- 


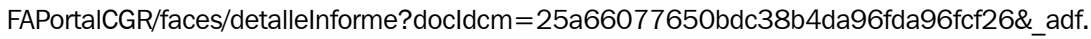
ctrl-state $=$ szo3fw7xj_19

Covarrubias, F., lararrazaval, I., \& Morandé, M. de los A. (2011). Sistema Integrado de Información Social: Chile. En La efectividad de las redes de protección social: El rol de los sistemas integrados de información social en seis países de América Latina (Salesianos Impresores, Vols. 1-500). Santiago, Chile: Inter-American Development Bank.

Departamento Nacional de Planeación (2007). Mecanismos de Focalización. Cuatro casos de estudio. (p. 34). Bogotá, Colombia. Recuperado a partir de https://colaboracion.dnp.gov. co/CDT/Desarrollo\%20Social/mecanismos_focalizacion_1.pdf

Herrera, R., Larrañaga, O., \& Telias, A. (2010). La Ficha de Protección Social. En Las nuevas políticas de protección social en Chile (pp. 265-296). Santiago: Uqbar Editores.

Larrañaga, 0. (2010). Las nuevas políticas de protección social en perspectiva histórica. En Las Nuevas Políticas de Protección Social en Chile (p. 300). Santiago: Uqbar Editores.

Larrañaga, O., Falck, D., Herrera, R., \& Telias, A. (2014). De la Ficha de Protección Social a la Reforma de la Focalización.

Ministerio de Desarrollo Social (2010). Comité de Expertos Ficha de Protección Social Octubre 2010 (p. 128). Santiago, Chile: MDS.

Ministerio de Desarrollo Social (2016a). Guía de procedimientos para Actualizar Rectificar o Complementar información al RSH. Santiago. Recuperado a partir de http://www.registrosocial. gob.cl/wp-content/uploads/2016/01/Guia-de-procedimientos-para-Actualizar-Rectificar-oComplementar-informaci\%C3\%B3n-al-RSH_Agosto-2016.pdf

Ministerio de Desarrollo Social (2016b). Informe Política Social Chilena (Informe de Política Social No. 6) (p. 204). Santiago de Chile: Ministerio Desarrollo Social. Recuperado a partir de http://www.ministeriodesarrollosocial.gob.cl/pdf/upload/Informe_de_Desarrollo_Social_2016.pdf

Ruvalcaba, N., \& Alfredo, M. (2006). Modelos y regímenes de bienestar social en una perspectiva comparativa: Europa, Estados Unidos y América Latina. Desacatos, (21), 109-134.

World Bank. (s. f.). Measuring income and poverty using Proxy Means Tests. Dhaka, Bangladesh. Recuperado a partir de https://olc.worldbank.org/sites/default/files/1.pdf

PARA CITAR ESTE ARTÍCULO:

Contreras Álvarez, J. y Figueroa Aillañir, K. (2018). "Desde la ficha de protección social al registro social de hogares, el nuevo instrumento de focalización en Chile. Una perspectiva desde los actores locales", DAAPGE, año 18, № 30 (ene-jun), 2018, pp. 129-163. Santa Fe, Argentina: UNL. 